None of our pinealectomized hamsters with tumours survived for more than 38 days after inoculation. It is difficult to draw any conclusions from this small group of hamsters, especially because all these tumours had ulceration, necrosis and consequent massive infection. Fortner et al. ${ }^{13}$ have reported a host survival time varying from 34 to 82 days after inoculation of this tumour. They also reported that there was always a high incidence of lung metastases and evidence of other visceral metastases from this tumour at the time of death of these animals. But the remarkable rapidity of metastatic spread observed in this experiment after pinealectomy was not observed on any occasion by Fortner et $a l . .^{13}$ and was corroborated by our two sets of controls.

The data obtained from this investigation tend to support a concept that the pineal body exerts some control on the growth and spread of pigmented neoplasms in hamsters. These experiments, however, do not explain whether the control is mediated by way of a pineal hormone which acts on melanophores or whether ablation of pineal per se depresses host resistance to tumours and homografts. Further experiments dealing with nonpigmented tumours in albino rats are at the moment in progress in order to elaborate these points.

We thank Professor R. Warwick for his help in the preparation of this report.

Department of Anatomy, T. K. DAs Gupta Guy's Hospital Medical School, London, S.E.1,

and

Department of Surgery,

Memorial Sloan Kettering Cancer Center,

New York.

' Jordan, H. E., Amer. J. Anat., 12, 249 (1911).

'Jordan, H. E., Anat. Rec., 22, 275 (1921).

${ }^{3}$ Rio-Hortega, P. del, Arch. Neurol., 3, 359 (1922).

- Rio-Hortega, P. del, Arch. Neurol, , 9, 26 (1929).

"Rio-Hortega, P. del, Arch. Neurol., 9, 139 (1929).

${ }^{6}$ Santamarina, E., and Meyer Arndt, J., Acta Histochem., 3, 1 (1956).

Santamarina, E., and Meyer Arndt, J., Canad. J. Biochem. Physiol., 36, 227 (1958).

${ }^{8}$ Clemo, G. R., and Duxbury, F. K., J. Chem. Soc., 1795 (1950).

'Huxley, J.S., and Hogben, L. T., Proc. Roy. Soc., B, 93, 26 (1922).

${ }^{10}$ Bors, O., and Rolston, W. C., Proc. Soc. Exp. Biol. and Med., 77, 807 (1951).

"Wyman, L. C., J. Exp. Zool., 40, 161 (1924).

${ }^{12}$ Das Gupta, T., and Terz, J., (submitted for publication).

's Fortner, J. G., Mahy, A. G., and Schrodt, G., Cancer Res., 21 (Suppl.) 161 (1981).

\section{Induction of Amyloidosis by Cadmium}

Aмýoidosis has been produced in experimental animals by injecting a variety of substances, most of them proteinaceous ${ }^{1}$. We have found that a simple chemical, cadmium, given to rabbits as cadmium chloride in relatively small doses over a long period of time will produce a severe form of amyloidosis.

The dosage chosen was one which had been found by Kench $^{2}$ to produce a proteinuria in rabbits similar to that found in humans after prolonged exposure to cadmium. Now Zealand outbred rabbits were injected with cadmium chloride in a dose of $1 \mathrm{mg} / \mathrm{kg} /$ day, 5 days a week. Two injection schedules were used. The first group of three animals received cadmium for an 8 week period. They were rested for 10 weeks and then reinjected for 4 weeks. They received an average total dose of $224 \mathrm{mg}$ of cadmium chloride $(68 \mathrm{mg} / \mathrm{kg})$. They were killed at the end of the second injection poriod (22 weeks after the first injection). The second group of three animals received the cadmium for 9 weeks. One animal died of unknown causes after 6 weeks. The two that survived received an average total dose of $127 \mathrm{mg}$ of cadmium chloride (47 $\mathrm{mg} / \mathrm{kg}$ ). They were biopsied 20 weeks after completion of the injections ( 30 weeks after the first injection) and were killed for complete autopsies 60 weeks after the first injection.
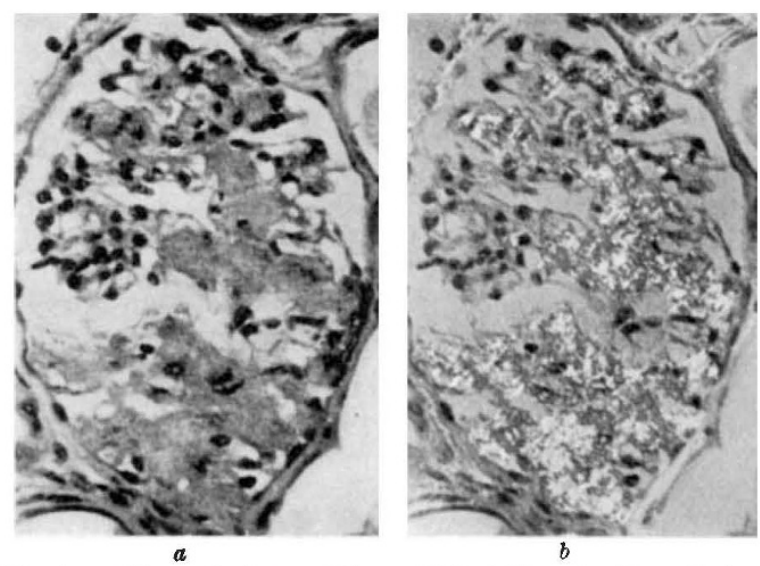

Fig. 1. $a$, Glomerulus in renal tissue obtained 30 weeks after cadmium treatment was begun, showing the amorphous amyloid occupying mos of the glomerular tuft. Congo red $(\times c .260)$. $b$, Polarized light micrograph of the same glomerulus as in Fig. 1, showing the birefringence of amyloid stained with Congo red $(x c, 260)$.

The tissue obtained at biopsy or autopsy was processed both for light and for electron microscopy. Sections stained with Congo red were also examined by polarized light and fluorescence microscopy to detect the characteristic birefringence and fluorescence of amyloid stained with Congo red. Thin sections were examined in the electron microscope to detect the fibrils characteristic of amyloid in tissue ${ }^{1}$.

Histological examination revealed a small amount of amyloid in the glomeruli of animals killed at 22 weeks. The deposits involved about 10 per cent of each glomerulus. Far more amyloid was seen in the kidneys of the animals biopsied at 30 weeks, although these animals had received a smaller dose of cadmium, and autopsy of the same animals at 60 weeks revealed massive involvement of the kidney with amyloid; almost every part of each glomerulus was replaced by material which had features characteristic of amyloid. Fig. Ia shows a severely affected glomerulus in the tissue obtained at 30 weeks, stained by the Congo red technique. Fig. $1 b$ shows the same glomerulus examined with polarized light, and showing the birefringence which is so typical of amyloid stained with Congo red. The identity of this material as amyloid was also established by electron microscopy. In addition to renal involvement, the animals killed at 60 weeks also showed extensive infiltrates in the spleen and the liver.

People who work with cadmium develop renal tubular lesions $s^{3}$ and similar lesions have been found in rabbits ${ }^{4}$ and rats ${ }^{5}$ injected with cadmium. Amyloidosis has not, however, been described previously either in man or in animals with cadmium poisoning. Few of the animal studies have been carried out for a period as long as that reported here, and the failure of earlier workers to find this lesion may be due to the fact that the animals were not kept alive long enough to develop amyloidosis. The absence of amyloidosis in men who have been exposed for periods up to 15 years does, however, suggest that species differences in the susceptibility to cadmium may also be present.

University of Texas,

J. BAUM

H. G. WORTHEN

Southwostern Medical School,

Dallas, Texas.

Received October 12, revised November 24, 1966.

${ }^{1}$ Cohen, A. S., Intern. Rev. Exp. Pathol., 4, 159 (1965).

"Kench, J. E., Wells, A. R., and Smith, J. C., S. Afric. Med. J., 36, 390 (1962).

${ }^{3}$ Kazantizis, G., Flynn, F. V., Spowage, J. S., and Trott, D. G., Qqait. J. Med., 32,165 (1963).

4 Axelsson, B., and Piscator, M., Arch. Environ. Health, 12, 360 (1966).

s Bonnell, J. A., Ross, J. H., and King, E., Brit. J. Indust. Med., 17, 69 (1959). 